\title{
Comparison of Cold Technique Tonsillectomy and Thermal Welding Tonsillectomy at Different Age Groups
}

\section{Arif Sanlı, Gazi Yildiz, Banu Atalay Erdogan, Mustafa Paksoy, Gokhan Altin, Muhammed Ali Ozcelik}

Department of Otolaryngology, Kartal Dr. Lutfi Kirdar Education

and Research Hospital, Istanbul, Turkey

Received October 3, 2016; Accepted March 9, 2017.

Key words: Tonsillectomy - Thermal welding - Cold technique - Postoperative pain

Abstract: The aim of this study is to compare objectively advantages and disadvantages of cold technique tonsillectomy and thermal welding tonsillectomy at the same case. A total of 100 patients, 53 patients younger than 12 years of age and 47 patients elder than 12 years of age, were included in this study. Tonsillectomy was performed by using cold technique on the right side of the palatine tonsils and thermal welding on the left side. Right and left sides were compared regarding perioperative bleeding, surgical dissection time, postoperative pain scale at the $1^{\text {st }}$ and $7^{\text {th }}$ day and postoperative bleeding parameters. Perioperative bleeding was found to be higher in cold technique side in patients younger than 12 years of age $(p<0.001)$. Postoperative pain score on the day 1 was significantly higher in cold technique side, whereas it was found to be higher in thermal welding side at postoperative day $7(p<0.001)$. Perioperative bleeding was found to be significantly higher in cold technique side $(p<0.001)$ and surgical dissection time of thermal welding was found to be longer $(p<0.001)$ in patients elder than 12 years of age. Postoperative pain score at the day 1 and day 7 was found to be higher in thermal welding side $(p<0.001)$. Postoperative pain score at the day 1 and day 7 were statistically significantly higher in patients elder than 12 years of age. As a result, both techniques have its unique superior aspects and both can be applied as a routine tonsillectomy technique.

Mailing Address: Assoc. Prof. Banu Atalay Erdogan, MD., Department of Otolaryngology, Kartal Dr. Lutfi Kirdar Education and Research Hospital, 34890 Cevizli Kartal, Istanbul,Turkey; e-mail: banuatalay81@gmail.com 


\section{Introduction}

The most commonly performed operation at otorhinolaryngology clinics is tonsillectomy and recurrent tonsillitis, airway obstruction, peritonsillar abscess, asymmetric tonsils and neoplasms are common indications. Tonsillectomy methods include cold dissection technique, electrosurgical techniques (monopolar and bipolar cautery), thermal welding, harmonic scalpel technique, argon plasma coagulation technique, $\mathrm{CO}_{2}$ and KPT-532 laser techniques (Younis and Lazar, 2012). Partial or subtotal tonsillectomy techniques (tonsillotomy) are guillotine (slud) technique, cryogenic tonsillotomy technique, laser tonsillotomy technique and bipolar electrosurgical tonsillotomy technique (Birkent and Akcam, 2005). Various surgical methods are developed due to problems such as postoperative bleeding, pain and dysphagia. New techniques are defined day by day. Studies comparing various techniques are also increasing at that rate in parallel with these developments (Krishna et al., 2004). Classic cold technique is one of the oldest methods and advantages and disadvantages of a new technique are often compared with this old method. There are studies comparing the various aspects of conventional tonsillectomy with bipolar electro cautery, thermal welding, intracapsular tonsillotomy, laser tonsillectomy, coblation plasma kinetic tonsillectomy and LigaSure-assisted tonsillectomy (Sayin and Cingi, 2012). Although current techniques have advantages and disadvantages, technique for minimal pain, maximum safety and effective tonsillectomy still remains uncertain (Stavroulaki et al., 2007). In our study, perioperative bleeding, surgical dissection time, postoperative pain scale of day 1 and 7 and postoperative bleeding parameters of thermal welding and cold dissection techniques were compared in different age groups. Considering the relevant parameters, defining the better technique affects the morbidity associated with operation.

\section{Material and Methods}

This study is a prospective randomized study. The study was conducted in Department of Otolaryngology at Kartal Dr. Lutfi Kirdar Education and Research Hospital between August 2011 and December 2013. Recurrent tonsillitis, upper airway obstruction and asymmetric tonsils were detected as indications. Patients with coagulation disorders or peritonsillar abscess history were excluded from the study. Ethics committee approval and informed consents from parents of pediatric population and from adult population were received. Patients were randomly included into the study. Right palatine tonsil was dissected by cold technique method and left palatine tonsil was dissected by thermal welding method during tonsillectomy operations in the same center. Operations were performed with the same surgeon. All operations were performed under general endotracheal anesthesia. Standard anesthesia and drug protocol were preferred in all patients.

Thermal welding system consists of a sterile forceps (ENTceps; Starion Instruments Corp., Sunnyvale, CA, USA), double-controlled foot pedal and universal 


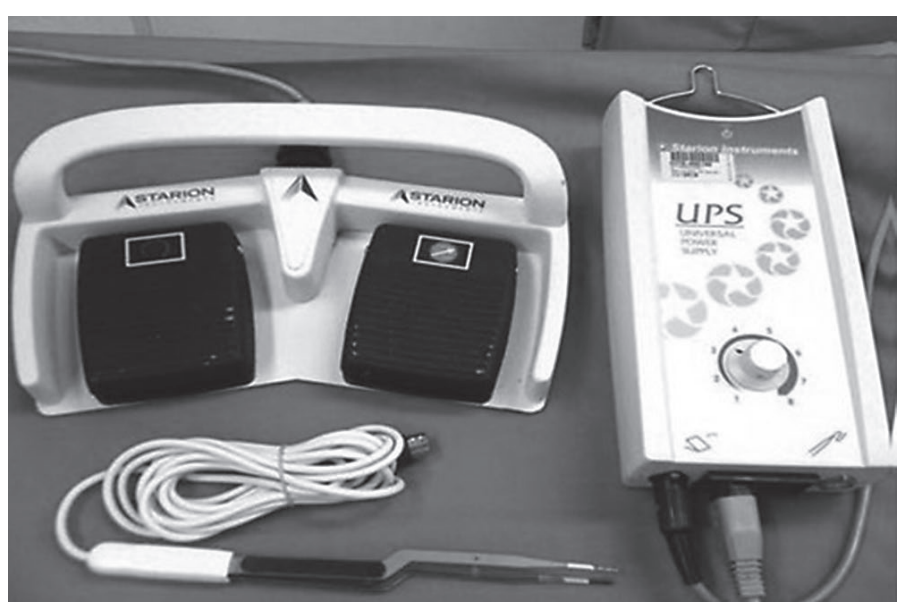

Figure 1 -Thermal welding system - Sterile forceps (ENTceps), double-controlled foot pedal and universal power supply (UPS).

power supply (UPS; Starion Instruments Corp., Sunnyvale, Ca, USA) (Figure 1). Heater system at the distal end of thermal welding system is activated by the pedestal pedal structure and proteins in the tissues are denatured and cut. Right pedal was used for tissue ablation and left pedal was used for the cutting process without opening the ends of the forceps. Thermal welding system is one of the extra capsular tonsillectomy techniques and devices were prepared in accordance with the operating instructions for that system. UPS setting was set to 3.5 for tonsillectomy. Starting from the upper pole of the tonsil to the lower pole, ablation and cutting was done with forceps.

Cold technique tonsillectomy was started with plica semilunaris incision of right tonsil and tonsillectomy was completed with classical dissection methods. No preoperative and/or postoperative anesthetic or analgesic drugs were injected to both tonsils. Time from tonsillar plica semilunaris incision to tonsil excision was recorded and bleeding was determined by measuring the blood accumulated in the extractor bag. Patients were kept in hospital for 24 hours for postoperation observation; patients with stable vital signs and provided oral feeding were discharged. Patients younger than 12 years of age were given $3 \times 1$ paracetamol suspension and patients elder than 12 years of age were given $3 \times 1$ paracetamol tablets for postoperative pain control. All patients got the same dose at the same time. Wong-Baker visual analogue scale and visual analog scale were used as pain scales for pediatric populations and adult group, respectively (Figures 2 and 3). Patients were questioned for pain on postoperative day 1 and most of the patients were discharged on postoperative day 1. Cooperative problem during postoperative pain questioning in patients younger than 12 years of age was exceeded by taking help from parents. Patients who come to the follow-up examinations on postoperative day 7 were evaluated. Patients were questioned 


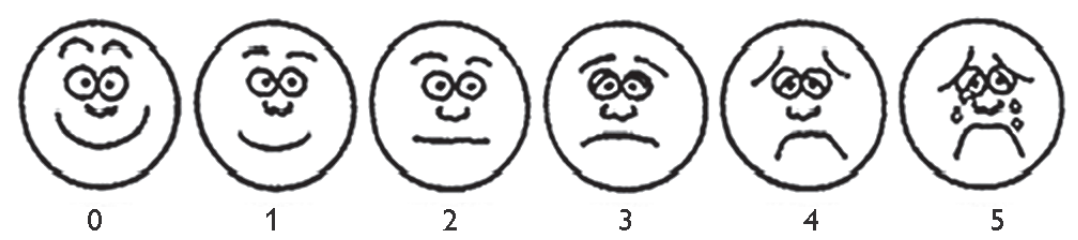

Figure 2 -Wong-Baker visual analogue scale.

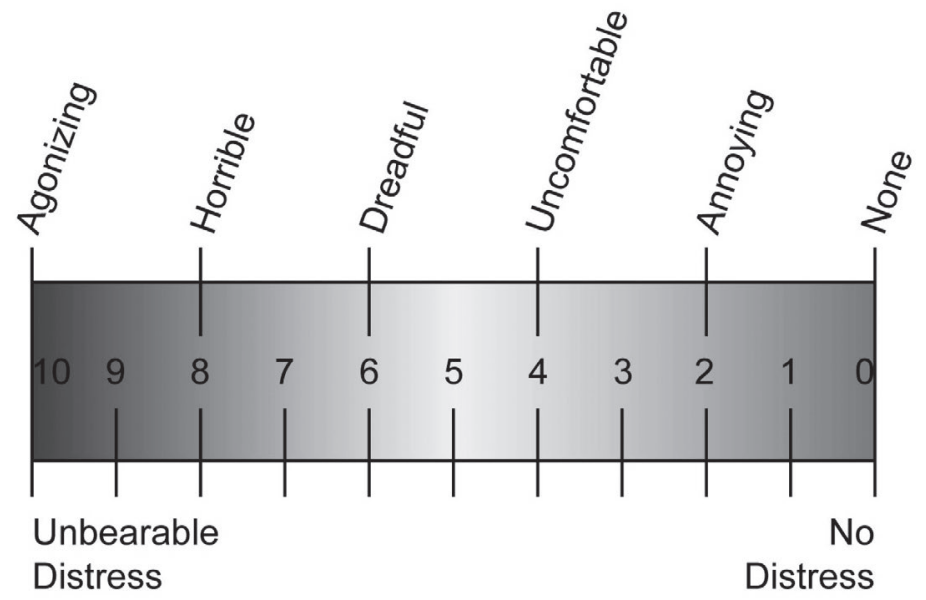

Figure 3 -Visual analogue scale.

again with pain scales and information was taken from the patients whether frequency and amount of drug use had changed or not.

Pearson's chi-square, independent samples t-test were used for statistical analysis of the study and $p<0.05$ was considered significant.

\section{Results}

106 tonsillectomies were assessed in 53 patients younger than 12 years of age. Of the patients, 23 (43.4\%) were female and 30 (56.6\%) were male. The mean age of the patients was $6.71 \pm 2.14$ (min-max: $3-11)$. Right and left sides were compared regarding perioperative bleeding, surgical dissection time, postoperative pain score at the $1^{\text {st }}$ and $7^{\text {th }}$ day, and postoperative bleeding parameters. Perioperative blood loss was significantly higher in the cold technique side $(p<0.001)$. Surgical dissection time was longer in patients undergoing welding $(p<0.001)$. Postoperative pain at the day 1 was observed to be higher in cold technique side and it was statistically significant higher at the day 7 in thermal welding side $(p<0.001 ; p<0.001)$.

Postoperative bleeding was observed in only $0.9 \%$ of patients $(n=1)$. Bleeding was observed in the patient in thermal welding side. No residual tissue was seen in any of the patients (Table 1). 
Table 1 - Comparison of cold technique tonsillectomy and thermal welding method according to perioperative bleeding (millilitres), surgical dissection time (minutes) and postoperative pain in younger than 12-year-old patients

\begin{tabular}{lccc}
\hline & $\begin{array}{c}\text { Cold technique } \\
\text { tonsillectomy }(\mathrm{n}=53)\end{array}$ & $\begin{array}{c}\text { Thermal welding } \\
\text { method }(\mathrm{n}=53)\end{array}$ & \multirow{2}{*}{$\mathrm{P}^{*}$} \\
\cline { 2 - 4 } & mean $\pm \mathrm{SD}$ & mean \pm SD & \\
\hline Perioperative bleeding & $18.8 \pm 15.61$ & $5.10 \pm 4.99$ & 0.000 \\
Surgical dissection time & $5.80 \pm 2.74$ & $11.26 \pm 4.12$ & 0.000 \\
Postoperative pain at $1^{\text {st }}$ day & $1.68 \pm 1.67$ & $0.57 \pm 1.15$ & 0.000 \\
Postoperative pain at $7^{\text {th }}$ day & $0.28 \pm 1.15$ & $1.15 \pm 2.02$ & 0.000 \\
\hline
\end{tabular}

$*_{\mathrm{p}}<0.05$ - independent samples $t$-test

Table 2 - Comparison of cold technique tonsillectomy and thermal welding method according to perioperative bleeding (millilitres), surgical dissection time (minutes) and postoperative pain in elder than 12-year-old patients

\begin{tabular}{lccc}
\hline & $\begin{array}{c}\text { Cold technique } \\
\text { tonsillectomy }\end{array}$ & $\begin{array}{c}\text { Thermal welding } \\
\text { method }\end{array}$ & P* \\
\cline { 2 - 3 } & mean \pm SD & mean \pm SD & \\
\hline Perioperative bleeding & $16.04 \pm 9.66$ & $4.85 \pm 3.23$ & 0.000 \\
Surgical dissection time & $6.60 \pm 2.68$ & $11.34 \pm 3.71$ & 0.000 \\
Postoperative pain at $1^{\text {st }}$ day & $3.47 \pm 1.79$ & $4.85 \pm 1.98$ & 0.001 \\
Postoperative pain at $7^{\text {th }}$ day & $1.17 \pm 1.24$ & $2.02 \pm 1.53$ & 0.004 \\
\hline
\end{tabular}

${ }^{*} \mathrm{p}<0.05$ - independent samples $t$-test

94 tonsillectomies were assessed in 47 patients elder than 12 years of age. Of the patients, 26 (55.3\%) were female and 21 (44.7\%) were male. The mean age of the patients was $25.36 \pm 11.44$ (min-max: 12-55). Right and left sides were compared regarding perioperative bleeding, surgical dissection time, postoperative pain score at the $1^{\text {st }}$ and $7^{\text {th }}$ day, and postoperative bleeding parameters.

Perioperative blood loss was significantly higher in the cold dissection side $(p<0.001)$. Surgical dissection time was longer in patients undergoing welding $(p<0.001)$. Postoperative pain at the day 1 and day 7 was observed to be lower in cold dissection side $(p=0.001 ; p=0.004)$. Postoperative bleeding was observed in only $2.1 \%$ of patients $(n=2)$. Bleeding was observed in 2 patients in thermal welding side. There was no difference between the incidences of bleeding in both groups $(p=0.153)$. No residual tissue was seen in any of the patients (Table 2). 
Table 3 - Comparison of cold technique tonsillectomy in groups of younger than 12 and elder than 12 years

\begin{tabular}{lcccc}
\hline & $\begin{array}{c}\text { Perioperative } \\
\text { bleeding }\end{array}$ & $\begin{array}{c}\text { Surgical } \\
\text { dissection time }\end{array}$ & $\begin{array}{c}\text { Postoperative } \\
\text { pain at } 1^{\text {st }} \text { day }\end{array}$ & $\begin{array}{c}\text { Postoperative } \\
\text { pain at } 7^{\text {th }} \text { day }\end{array}$ \\
\hline $\begin{array}{l}\text { Mean } \pm \text { SD } \\
\text { (younger than 12) }\end{array}$ & $18.8 \pm 15.61$ & $5.80 \pm 2.74$ & $1.68 \pm 1.67$ & $0.28 \pm 1.15$ \\
$\begin{array}{l}\text { Mean } \pm \text { SD } \\
\text { (elder than 12) }\end{array}$ & $16.04 \pm 9.66$ & $6.60 \pm 2.68$ & $3.47 \pm 1.79$ & $1.17 \pm 1.24$ \\
P $^{*}$ & 0.442 & 0.142 & 0.000 & 0.000 \\
\hline
\end{tabular}

${ }^{*} \mathrm{p}<0.05$ - independent samples $t$-test

Table 4 - Comparison of thermal welding method tonsillectomy in groups of younger than 12 and elder than 12 years

\begin{tabular}{lcccc}
\hline & $\begin{array}{c}\text { Perioperative } \\
\text { bleeding }\end{array}$ & $\begin{array}{c}\text { Surgical } \\
\text { dissection time }\end{array}$ & $\begin{array}{c}\text { Postoperative } \\
\text { pain at } 1^{\text {st }} \text { day }\end{array}$ & $\begin{array}{c}\text { Postoperative } \\
\text { pain at } 7^{\text {th }} \text { day }\end{array}$ \\
\hline $\begin{array}{l}\text { Mean } \pm \text { SD } \\
\text { (younger than 12) }\end{array}$ & $5.10 \pm 4.99$ & $11.26 \pm 4.12$ & $0.57 \pm 1.15$ & $1.15 \pm 2.02$ \\
$\begin{array}{l}\text { Mean } \pm \text { SD } \\
\text { (elder than 12) }\end{array}$ & $4.85 \pm 3.23$ & $11.34 \pm 3.71$ & $4.85 \pm 1.98$ & $2.02 \pm 1.53$ \\
P $^{*}$ & 0.776 & 0.923 & 0.000 & 0.002 \\
\hline
\end{tabular}

${ }^{*} \mathrm{p}<0.05$ - independent samples $t$-test

Parameters of the same tonsillectomy techniques in both groups were compared (Tables 3 and 4). No statistical significance was found regarding perioperative bleeding in both groups where welding tonsillectomy was performed ( $p>0.005)$. Surgical dissection time was not significantly different in comparing the two groups $(p>0.005)$. Pain scores at the postoperative day 1 and day 7 were significantly higher in patients elder than 12 years of age $(p<0.005)$. No statistical significance was found regarding perioperative bleeding in both groups where cold technique tonsillectomy was performed $(p>0.005)$. Surgical dissection time was not significantly different in comparing the two groups $(p>0.005)$. Pain scores at the postoperative day 1 and day 7 were significantly higher in patients elder than 12 years of age $(p<0.005)$.

\section{Discussion}

Tonsillectomy is the most common surgical operations in otorhinolaryngology clinics and constitute $20 \%$ of the operations. Many techniques are applied in surgery (Allford and Guruswamy, 2009). The comparison of different parameters of tonsillectomy techniques has been conducted in pediatric or adult age group 
in many studies (Sargi and Younis, 2007). The ideal technique should be fast, reliable, with less bleeding and pain and with quick recovery period. Although cold dissection tonsillectomy is the most common technique in surgical techniques, bipolar electro dissection tonsillectomy techniques are among alternates (Sezen et al., 2008). Though operative time and blood loss has been decreased with electro cautery technique, postoperative pain is a significant cause of morbidity. Thermal welding method is a variant of bipolar electro cautery and uses thermal energy instead of electricity for coagulating and dissecting soft tissue and blood vessels (Nunez et al., 2000). In recent years, a few new tonsillectomy techniques such as harmonic ultrasonic knife, coblator, laser or radiofrequency excisions that aim to reduce bleeding, postoperative pain and operation time have been proposed. Parameters such as reducing post-tonsillectomy morbidity, pain and dehydration, preventing postoperative bleeding and providing adequate oral intake are crucial in surgical technique selection (Parsons et al., 2006). Unlike other studies, we performed cold technique and thermal welding method to each patient's right and left palatine tonsil, respectively by creating two groups of patients as more and younger than 12 years of age. Parameters such as postoperative pain, bleeding status, perioperative bleeding and surgical dissection time were evaluated using two different techniques in the same patient. Swallowing functions, drug use patterns, adolescence and cooperative conditions were considered and two different groups were created with a boundary of 12 years of age.

Perioperative and delayed hemorrhage in tonsillectomy and adenotonsillectomy is seen at a rate from 1 to $5.7 \%$. Primary bleeding is reported to be seen in the first 24 hours' time after the operation and be more dangerous. Secondary hemorrhage is seen after the first 24 hours postoperatively and early measures should be taken, as both bleedings are life threatening particularly in children (Windfuhr, 2003). Besides surgical methods and applied hemostasis techniques, patient's coagulation parameters are also important. Features such as lately previous viral infection, perioperative and postoperative blood pressure are discussed to be effective in providing bleeding control (Licameli et al., 2008). Patients with those risk factors were excluded from the study. In a meta-analysis by Marret et al. (2003) they found an increased risk of bleeding with nonsteroidal anti-inflammatory drugs used in the postoperative period in patients undergoing tonsillectomy and suggested not to use drugs for reducing the likelihood of reoperation. This was taken into consideration and paracetamol was prescribed to patients after discharge.

In a study by Karatzias et al. (2005) on 50 patients, no measurable perioperative bleeding was found in pediatric and adult populations undergoing thermal welding tonsillectomy and no postoperative bleeding was reported. In a study by Stavroulaki et al. (2007) on 32 adult patients, perioperative bleeding was found to be significantly lower in the group treated with thermal welding. No postoperative bleeding was seen in the group treated with thermal welding and 3 patients had postoperative bleeding in the group treated with cold technique. Although 
postoperative bleeding was seen in the group treated with cold technique, difference was not statistically significant. In the study of Ersozlu et al. (2013) based on 213 adults and pediatric patients, postoperative bleeding was observed in both age groups but especially in adult age group.

In a study by Ozkiris et al. (2013) on 120 adult patients, cold technique, thermal welding and bipolar cautery were compared regarding intraoperative bleeding. The result was not statistically significant in patients with thermal welding and bipolar cautery techniques, but the amount of bleeding in the cold technique was found to be more in the comparison of two techniques to cold technique. No significant difference was found between the three groups regarding postoperative early or late bleeding (Ozkiris et al., 2013). In the retrospective study by Praveen et al. (2013) on 1,336 tonsillectomy patients, postoperative hemorrhage incidence was found to increase in coblation patients following tonsillectomy with coblation, cold technique, helica thermal and bipolar cautery. In a study by Chimona et al. (2008) on pediatric age group, perioperative bleeding was higher in the group treated with cold dissection when compared to cold technique radiofrequency and thermal welding tonsillectomy. No significant difference was found in thermal welding and radiofrequency groups. No significant difference was found between three techniques regarding postoperative bleeding (Chimona et al., 2008).

In our study, perioperative bleeding was found to be high in cold technique applied patients in both groups. No significant difference was observed regarding bleeding in the comparison of the two groups. When postoperative bleeding parameter was examined, postoperative bleeding occurred in 1 patient younger than 12 years of age and 2 patients elder than 12 years of age undergoing thermal welding and no statistical significance was detected in both groups.

Postoperative pain after tonsillectomy is one of the most important causes of morbidity restricting oral intake, causing dehydration and daily activity limitation (Polites et al., 2006). In addition, restriction of the pharyngeal muscle activity due to pain leads to reduction in the clearance of tonsil bed and as a result of may cause infection and bleeding (Belloso et al., 2006). Local or systemic steroid administration, local anesthesia and analgesia applications besides new surgical techniques generating low heat and temperature take place in postoperative pain relief (Rawlinson et al., 2011). Surgical techniques and instruments often affect pain more than pharmacological agents. Although cold tonsillectomy technique causes less tissue damage compared to tonsillectomy techniques using electricity and heat energy, postoperative pain relief is controversial. Nowadays commonly used techniques such as harmonic scalpel, coblator, thermal welding and bipolar cautery are used to reduce the postoperative pain. Despite recent developments, no techniques or devices with a definite advantage in postoperative pain reduction could not be identified (Tepe Karaca et al., 2013). Element providing thermal energy in the thermal welding system is a simple resistance wire heater operating with low voltage direct current. The active part of the device is the 
heater composed of nickel chrome resistance and thermal insulated rear part. This layer prevents nickel chrome wire heat spreading to other parts of the device. Depending on the heat diffusion in the nickel-chrome wire, the area of cut part is larger than the diameter of the wire. The heat in the tissue is sufficient to cut the tissue by direct vaporization. This temperature varies between $300-400{ }^{\circ} \mathrm{C}$. The temperature drops to 100 degrees as distance increases from the center of the wire (Treat, 2007). So we can say that thermal welding tonsillectomy is a more reliable method among hot tonsillectomy techniques in terms of tissue damage.

In the study by Stavroulaki et al. (2007) on adult tonsillectomy cases, thermal welding use has been shown to cause less postoperative pain than cold technique but Chimona et al. (2008) indicated that cold technique is more advantageous in postoperative pain control over thermal welding and radiofrequency application in pediatric patients. In a prospective randomized study conducted on adult patients by Parsons et al. (2006), radiofrequency tonsillectomy has been reported to decrease postoperative pain compared to electro cautery. In a single-blind randomized study by Oko et al. (2005) on pediatric patients, pain after tonsillectomy with blunt dissection was found to be significantly less than tonsillectomy with ultrasonic blades. In the study by Yilmaz et al. (2012) on 91 pediatric patients, postoperative pain with thermal welding has been found to be less. More pain in the cold technique has been connected to bipolar cautery use for intraoperative bleeding control (Yilmaz et al., 2012).

In our study, while postoperative pain on day 1 was significantly higher on cold technique applied side, it was detected higher on thermal welding side on day 7 in patients younger than 12 years of age. As perioperative bleeding was more on cold technique applied side, bipolar cautery, lasso and suture use requirements became more and edema in the tonsils due to that caused higher postoperative day 1 pain scores. Postoperative pain scores on day 1 and 7 on thermal welding sides was found to be significantly higher in patients elder than 12 years of age. This was associated with more tissue damage due to high temperature, more common and longer epithelialization and pseudo membrane appearance in the tonsils during recovery period. Regarding comparison of the two groups, postoperative day 1 and day 7 pain scores were found to be higher on cold technique applied side in patients elder than 12 years of age. Postoperative day 1 and day 7 pain scores were also elevated on thermal welding applied side in patients elder than 12 years of age.

Operation time and anesthesia time associated with it affects morbidity associated with tonsillectomy. In the study by Sezen et al. (2008) on 50 patients, the use of thermal welding has been found to significantly reduce operation time compared to cold technique method. In the study by Ozkiris et al. (2013), it was found to be significantly longer in cold technique patients compared to thermal welding and bipolar cautery. In the study by Yilmaz et al. (2012), no significant 
difference was detected in terms of operation time in patients undergoing thermal welding and cold technique.

In the literature, operation time has been identified as the time starting from placement of mouth opener to the end of the operation. But in our study, unlike other studies, two different techniques were applied in the same patient so comparing the duration of two techniques will not be objective as placement of mouth opener, operative field cleaning and tampon placement will unnecessarily extend the duration time of first technique. Therefore, we recorded the duration of the surgical dissection as time starting from initial incision to tonsillar pillars to complete excision. Surgical dissection time was statistically longer on thermal welding side in both groups.

\section{Conclusion}

Two tonsillectomy techniques were performed to the same patient, perioperative bleeding, postoperative pain at the day 1 and day 7 and surgery dissection time parameters were compared in two age groups. When all parameters are compared, thermal welding tonsillectomy in terms of bleeding and cold technique tonsillectomy in terms of postoperative pain surgery dissection time have been determined to be more appropriate. In both techniques, postoperative pain was found to be higher in patients elder than 12 years of age and significantly lower in patients younger than 12 years of age. As a result, we came to the conclusion that both techniques have its unique superior aspects and both can be applied as a routine tonsillectomy technique.

\section{References}

Allford, M., Guruswamy, V. (2009) A national survey of the anesthetic management of tonsillectomy surgery in children. Paediatr. Anaesth. 19, 145-152.

Belloso, A., Morar, P., Tahery, J., Saravanan, K., Nigam, A., Timms, M. S. (2006) Randomized-controlled study comparing post-operative pain between coblation palatoplasty and laser palatoplasty. Clin. Otolaryngol. 31(2), 138-143.

Birkent, H., Akcam, M. T. (2005) Tonsillectomy and adenoidectomy:Traditional and new techniques. Turkiye Klinikleri J. Surg. Med. Sci. 1, 16-25. (in Turkish)

Chimona, T., Proimos, E., Mamoulakis, C., Tzanakakis, M., Skoulakis, C. E., Papadakis, C. E. (2008) Multiparametric comparison of cold knife tonsillectomy, radiofrequency excision and thermal welding tonsillectomy in children. Int. J. Pediatr. Otorhinolaryngol. 72(9), 1431-1436.

Ersozlu, T., Yildirim, Y. S., Sarica, S. (2013) Comparison of pediatric and adult tonsillectomies performed by thermal welding system. Int. J. Otolaryngol. 2013, 265105.

Karatzias, G. T., Lachanas, V. A., Papouliakos, S. M., Sandris, V. G. (2005) Tonsillectomy using thermal welding system. ORL J. Otorhinolaryngol. Relat. Spec. 67, 225-229.

Krishna, P., LaPage, M. J., Hughes, L. F., Lin, S.Y. (2004) Current practice patterns in tonsillectomy and perioperative care. Int. J. Pediatr. Otorhinolaryngol. 68(6), 779-784.

Licameli, G. R., Jones, D. T., Santosuosso, J., Lapp, C., Brugnara, C., Kenna, M. A. (2008) Use of a preoperative bleeding questionnaire in pediatric patients who undergo adenotonsillectomy. Otolaryngol. Head Neck Surg. 139, 546-550. 
Marret, E., Flahault, A., Samama, C. M., Bonnet, F. (2003) Effects of postoperative, nonsteroidal, antiinflammatory drugs on bleeding risk after tonsillectomy: meta-analysis of randomized, controlled trials. Anesthesiology 98, 1497-1502.

Nunez, D. A., Provan, J., Crawford, M. (2000) Postoperative tonsillectomy pain in pediatric patients: Electrocautery (hot) vs cold dissection and snare tonsillectomy - a randomized trial. Arch. Otolaryngol. Head Neck Surg. 126, 837-841.

Oko, M. O., Ganly, I., Loughran, S., Clement, W. A., Young, D., Geddes, N. K. (2005) A prospective randomized single-blind trial comparing ultrasonic scalpel tonsillectomy with tonsillectomy by blunt dissection in a pediatric age group. Otolaryngol. Head Neck Surg. 133, 579-584.

Ozkiris, M., Kapusuz, Z., Saydam, L. (2013) Comparison of three techniques in adult tonsillectomy. Eur. Arch. Otorhinolaryngol. 270, 1143-1147.

Parsons, S. P., Cordes, S. R., Comer, B. (2006) Comparison of posttonsillectomy pain using the ultrasonic scalpel, coblator and electrocautery. Otolaryngol. Head Neck Surg. 134, 106-113.

Polites, N., Joniau, S., Wabnitz, D., Fassina, R., Smythe, C., Varley, P., Carney, A. S. (2006) Postoperative pain following coblation tonsillectomy: randomized clinical trial. ANZ J. Surg. 76(4), 226-229.

Praveen, C.V., Parthiban, S., Terry, R. M. (2013) High incidence of post-tonsillectomy secondary haemorrhage following coblation tonsillectomy. Indian J. Otolaryngol. Head Neck Surg. 65(1), 24-28.

Rawlinson, E., Walker, A., Skone, R., Thillaivasan, A., Bagshaw, O. (2011) A randomized controlled trial of two analgesic techniques for paediatric tonsillectomy. Anaesthesia 66, 919-924.

Sargi, Z., Younis, R. T. (2007) Tonsillectomy and adenoidectomy techniques: past, present and future. ORL J. Otorhinolaryngol. Relat. Spec. 69, 331-335.

Sayin, I., Cingi, C. (2012) Recent medical devices for tonsillectomy. Hippokratia 16(1), 11-16.

Sezen, O. S., Kaytanci, H., Kubilay, U., Coskuner, T., Unver, S. (2008) Comparison between tonsillectomy with thermal welding and the conventional "cold" tonsillectomy technique. ANZ J. Surg. 78(11), 1014-1018.

Stavroulaki, P., Skoulakis, C., Theos, E., Kokalis, N., Valagianis, D. (2007) Thermal welding versus cold dissection tonsillectomy: a prospective, randomized, single-blind study in adult patients. Ann. Otol. Rhinol. Laryngol. 116(8), 565-570.

Tepe Karaca, C., Celebi, S., Oysu, C., Celik, O. (2013) Does cooling the tonsillar fossae during thermal welding tonsillectomy have an effect on postoperative pain and healing? Eur. Arch. Otorhinolaryngol. 270, 363-366.

Treat, M. R. (2007) A new thermal device for sealing and dividing blood vessels. Available at: http://www. starioninstruments.com/PDFs/Treat.pdf (accessed 14 May 2007)

Windfuhr, J. P. (2003) Lethal post-tonsillectomy hemorrhage. Auris Nasus Larynx 30, 391-396.

Yilmaz, M., Duzlu, M., Catli, T., Ustun, S., Ceylan, A. (2012) Thermal welding versus cold knife tonsillectomy: a prospective randomized study. Kaohsiung J. Med. Sci. 28(5), 270-272.

Younis, R. T., Lazar, R. H. (2012) History and current practice of tonsillectomy. Laryngoscope 112(100), 3-5. 